\title{
Effect of soil resistivity on the design of sacrificial anode cathodic protection system
}

\author{
Dheya N. Abdulamer \\ Energy and Renewable Energies Technology Center (ERETC) \\ University of Technology
}

\section{Abstract:}

In this research, the effect of soil resistivity on the sacrificial cathodic protection of a pipeline steel of oil was studied. Sufficient sacrificial cathodic protection could be obtained at various soil resistivty for different types of anodes. High current output (2.98, 2.38 and $8.33 \mathrm{Amps}$ ) of $\mathrm{Zn}, \mathrm{Al}$ and $\mathrm{Mg}$ anodes respectively, are obtained at 25 ohms.cm soil resistivity. Simultaneous, for the same conditions, low numbers and large weights of anodes are required to satisfy protection.

$\underline{\text { Key words: }}$ Sacrificial anode cathodic protection, Impressed current cathodic protection, backfill, Soil resistivity

نم في هذا البحث دراسة تأثير مقاومة التربة لانواع مختلفة من الاقطاب على الحماية الكاثودية

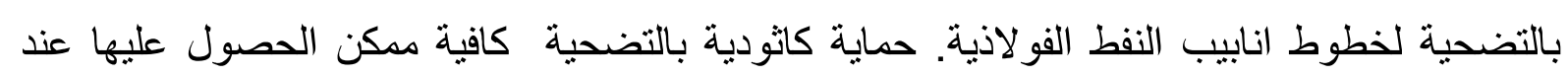
مقاوميات متغيرة للتربة لانواع مختلفة من الاقطاب. تيار عالي (2.98, 2.38 و 8.33 امبير) خارجة

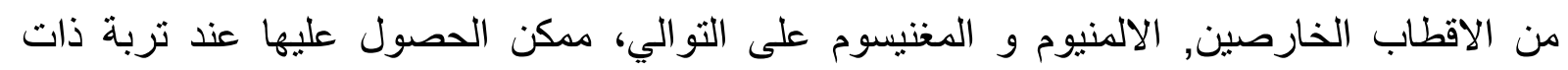

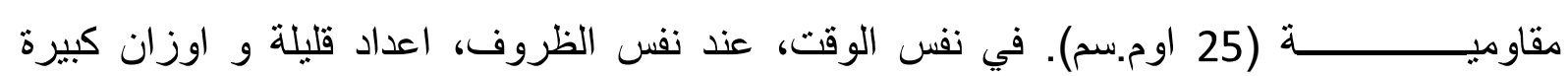
للاقطاب مطلوبة لتحقيق الحماية. 


\section{Introduction:}

Corrosion is an electrochemical process in which a current leaves a structure at the anode site, passes through an electrolyte, and re-enters the structure at the cathode site. The anode potential is more negative than the cathode potential, and this difference is the driving force for the corrosion current. The total system - anode, cathode, electrolyte, and metallic connection between anode and cathode is termed a corrosion cell [1].

Buried steel lines have many important industrial applications such as petroleum oil transportation across countries. Protecting steel against corrosion using paints, coating by organic or inorganic coats, metallic coating using either noble or less noble metals, using corrosion inhibitors, application of cathodic protection, etc. One of the important and promising applications is corrosion protection [2].

Cathodic protection (CP) is a method to reduce corrosion by minimizing the difference in potential between anode and cathode. This is achieved by applying a current to the structure to be protected (such as a pipeline) from some outside source [3].

Cathodic protection is an electrochemical technique in which a cathodic (protective) potential is applied to an engineering structure in order to prevent corrosion from taking place, and this implies that Ohm's law, $E=I R$, can be used to control the potential, as well as the current [4].

There are two principal methods of applying cathodic protection. The impressed current technique and the use of sacrificial anodes. Impressed current cathodic protection (ICCP) systems are used throughout the world to provide cathodic protection for pipelines, ship hulls, offshore production platforms, 
water and wastewater treatment equipment, tank farms, and underground storage tank systems [5].

When two different metals are immersed in the same electrolyte solution they will usually exhibit different electrode potentials. If they are then connected by an electronic conductor, there will be a tendency for the potentials of the two metals to move towards one another, they are said to mutually polarise. The polarisation will be accompanied by a flow of ionic current through the solution from the more negative metal (the anode) to the more positive metal (the cathode), and electrons will be transferred through the conductor from the anode to the cathode. It is said to be cathodically protected. Conversely, in supplying electrons to the cathode the anode will be consumed more rapidly, and thus will act as a sacrificial anode [6].

The sacrificial anode technique uses the natural potential difference that exists between the structure and a second metal in the same environment to provide the driving voltage. No power source is employed. Moreover, the dissolution of the second metal, that is, the sacrificial anode, provides the source of electrons for cathodic polarization of the structure. Thus, while the impressed-current anode may be more noble or more base than the protected structure because the power source forces it to act as an anode, the sacrificial anode must be spontaneously anodic to the structure, that is, be more negative in the galvanic series for the given

environment. Thus, in principle, zinc, aluminum, or magnesium could be used to protect steel, and iron to protect copper. Figure (1) illustrates the use of a sacrificial anode for cathodic protection [7]. 


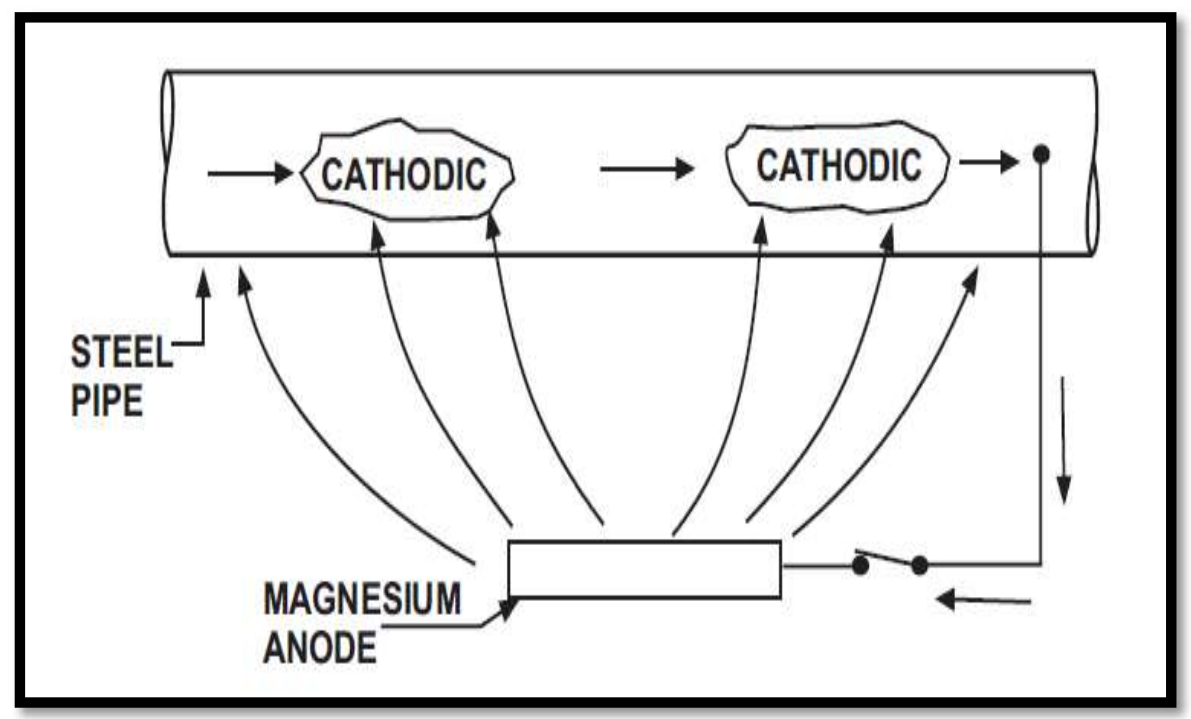

Fig.(1) sacrificial cathodic protection system [8].

\section{Theoretical background:}

Before deciding which type, galvanic or impressed current cathodic protection system will be used and before the system is designed, certain preliminary data must be gathered.

\section{a. Dimensions of structure to be protected}

These data are used to calculate the surface area to be protected structure.

\section{b. Electrolyte resistivity survey}

A structure's corrosion rate is inversly proportional to the electrolyte resistivity. Without cathodic protection, as electrolyte resistivity decreases, more current is allowed to flow from the structure into the electrolyte; thus, the structure corrodes more rapidly. Resistivity can be measured either in a laboratory or at the site with the proper instruments. The resistivity data will be 
used to calculate the sizes of anodes and rectifier required in designing the cathodic protection system.

\section{c. Structure versus electrolyte potential survey}

The potential between the structure and the electrolyte will give a direct indication of the corrosivity. The potential requirement for cathodic protection is a negative (cathodic) potential of at least 0.85 volt as measured between the structure and a saturated copper-copper sulfate reference electrode in contact with the electrolyte. A potential which is more positive than -0.85 volt would probably be corrosive, with corrosivity increases as the negative value decreases (becomes more positive).

\section{d. Current requirement}

A critical part of design calculations for cathodic protection systems on existing structures is the amount of current required per square foot (called current density) to change the structure's potential to -0.85 volt. A well coated structure will require a very low current density (about 0.05 milliampere per square meter), an uncoated structure would require high current density (about 10 milliamperes per square meter). The average current density required for cathodic protection is 2 milliamperes per square meter of bare area. The amount of current required for complete cathodic protection can be determined by three ways [9]:

1- An actual test on existing structures using a temporary cathodic protection setup. 
2- A theoretical calculation based on coating efficiency. A coating's resistance decreases greatly with age and directly affects structure to electrolyte resistance for design calculations.

3- An estimate of current requirements using tables based on field experience.

(a) The second and third methods above can be used on both existing and new structures.

(b) Current requirements can be calculated based on coating efficiency and current density (current per square foot) desired. The efficiency of the coating as supplied will have a direct effect on the total current requirement, as equation. 1 shows:

$$
\mathrm{I}=(\mathrm{A})\left(\mathrm{I}_{\mathrm{i}}\right)(1.0-\mathrm{CE})
$$

Equation. 1 may be used when a current requirement test is not possible.

\section{Determining design of cathodic protection system:}

The following eight steps are required when designing galvanic cathodic protection systems.

1- Review soil resistivity. The site of lowest resistivity will likely be used for anode location to minimize anode-to-electrolyte resistivity. 
2- Select anode, galvanic anodes are usually either magnesium or zinc. Zinc anodes are used in extremely corrosive soil (resistivity below 2000 ohmcentimeters.

3- Calculate net driving potential for anodes.

4- Calculate number of anodes needed to meet groundbed resistance limitations.

The total resistance of the galvanic circuit is given by :

$$
\mathrm{R}_{\mathrm{T}}=\mathrm{R}_{\mathrm{a}}+\mathrm{R}_{\mathrm{w}}+\mathrm{R}_{\mathrm{c}}
$$

The total resistance also can be found by using :

$$
\mathrm{R}_{\mathrm{T}}=\mathrm{E} / \mathrm{I}
$$

$\mathrm{R}_{\mathrm{c}}$ in equation. 2 can be calculated by using :

$$
\mathrm{R}_{\mathrm{c}}=\mathrm{R} / \mathrm{A}_{\mathrm{c}}
$$

Assuming $\mathrm{R}_{\mathrm{w}}$ in equation. 2 is negligible, that anode to electrolyte resistance can then be calculated from equation. 5 : 


$$
\mathrm{R}_{\mathrm{a}}=\mathrm{R}_{\mathrm{T}}-\mathrm{R}_{\mathrm{c}}
$$

To calculate the number of anodes required the following equation is used

$$
\mathrm{N}=0.0052 \rho / \mathrm{Ra}(\mathrm{L})[\ln 8 \mathrm{~L} / \mathrm{d}-1]
$$

5- Calculate number of anodes for system's life expectancy. Each cathodic protection system will be designed to protect a structure for a given number of years. To meet this lifetime requirement, the number of anodes must be calculated using equation. 7 :

$$
\mathrm{N}=\mathrm{L}(\mathrm{I}) / 49.3(\mathrm{~W})
$$

For galvanic cathodic protection systems, the anodes should be spaced equally along the structure to be protected [9].

The soil resistivities $(25,50,600,1000,5000 \Omega . \mathrm{cm})$ represent moderate to severe conditions of large extent of land in north Iraq - Turkey pipeline extending from Nineva to Um - Qaser in Basrah as shown in the Table (1).

This condition without effect of bacteria and any obstacle [10]. 
Table (1) Soil resistivtiy in the large extent of Iraq land [10].

\begin{tabular}{|c|c|c|c|}
\hline $\begin{array}{c}\text { Concentration } \\
\text { NaCl \% }\end{array}$ & $\begin{array}{c}\text { NaCl } \\
\text { content } \\
\text { g/I }\end{array}$ & $\begin{array}{c}\text { Conductivity } \\
\mu \Omega / \mathrm{cm}\end{array}$ & $\begin{array}{c}\text { Resistivity } \\
\Omega . c m\end{array}$ \\
\hline 0.01 & 0.1 & 200 & 5000 \\
\hline 0.05 & 0.5 & 1000 & 1000 \\
\hline 0.1 & 1 & 1666.66 & 600 \\
\hline 1 & 10 & 20000 & 50 \\
\hline 3 & 30 & 40000 & 25 \\
\hline
\end{tabular}

\section{Design of Sacrificial Anode cathodic protection (SACP) system:}

The first step in the design involves calculating the total current required (I) for protecting steel pipe against corrosion. Dimensions of steel pipe and anods have been used in this research described in the Table (2).

Equation .1 has been used to determine (I). pipeline to soil resistance $\mathrm{R}_{\mathrm{c}}$ negligible because of pipe consider to be bare so current density have been used in the search equal to $10 \mathrm{~mA}$. The anode lead wire resistance $\mathrm{R}_{\mathrm{w}}$ also negligible. The total circuit resistance $R_{T}$ and anode to electrolyte resistance $R_{a}$ have been estimated using equations. 3 and 5 respectively.

The data obtained from these equations depend mainly on the variations of soil resistivity $(\rho)$. Data of soil resistivity derived from Table 1, which is represent Soil resistivtiy in large extent of Iraq land. For various soil resistivity, number of anodes required determined from equation. 6 which it depend on the dimension of anode. So on weights of anodes required depend on the values of anodes number, equation. 7 have been used to calculate these weights. 
The output current obtained these Sacrificial Anodes cathodic protection designed for 15 year under the following conditions that mentioned in the Table (2), which represent the main consideration for design Sacrificial Anode cathodic protection for $100 \mathrm{~m}$ oil pipeline. Arrangement of Sacrificial Anode cathodic protection system can be shown in the figure (2).

Table (2): Boundary conditions of design SACP system

\begin{tabular}{|c|c|c|}
\hline Structure & \multicolumn{2}{|c|}{ Description } \\
\hline Steel pipe & $\mathrm{d}_{\mathrm{s}}=30 \mathrm{~cm}$ & $\mathrm{~L}_{\mathrm{s}}=10000 \mathrm{~cm}$ \\
& & $\mathrm{I}_{\mathrm{i}}=10 \mathrm{~mA}$ \\
\hline Zinc anode & $\mathrm{D}=12 \mathrm{~cm}$ & $\mathrm{~L}=48 \mathrm{~cm}$ \\
Aluminum anode & & \\
& & \\
\hline
\end{tabular}

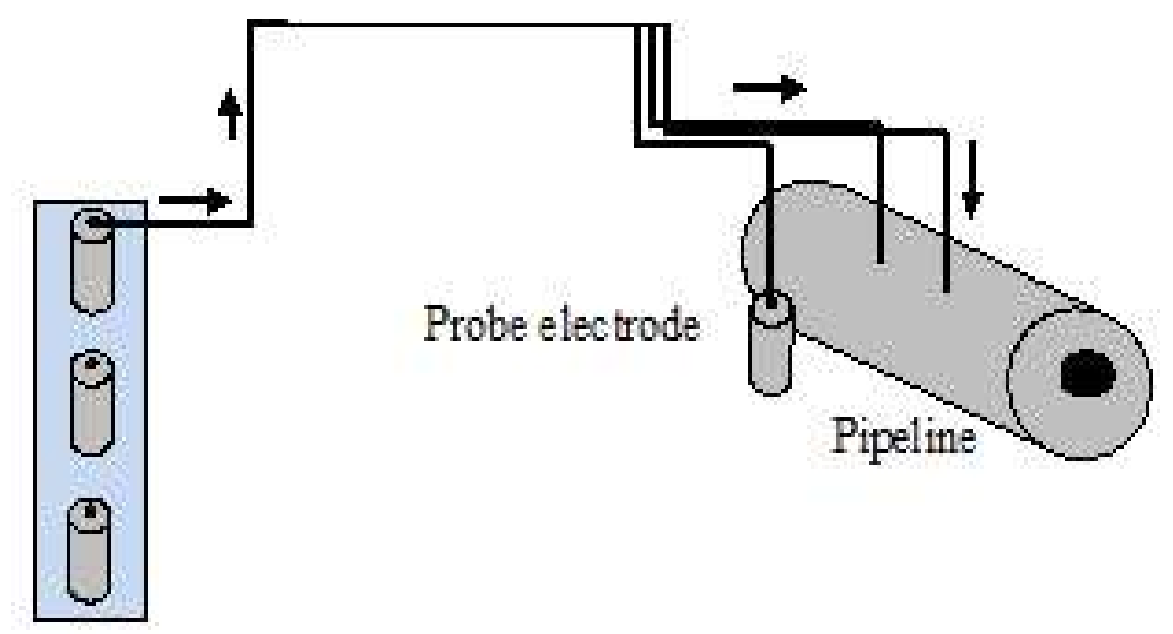

Backfill

Fig.(2) sacrificial anode cathodic protection system. 


\section{Results and discussion:}

Many parameters influence on the design of sacrificial cathodic protection. Soil resistivity represent the main factor that should be take into account during design of sacrificial cathodic protection. Figure (3) shows the relationship between current output of $\mathrm{Zn}$ anode verses soil resistivity and during this figure, the current output of zinc anode decrease with increased of soil resistivity. This behavior clearly shown in figures (4\& 5) for $\mathrm{Al}$ and $\mathrm{Mg}$ anodes respectively.

Large number of anodes (673 $\mathrm{Zn}$ anode) required in the high soil resistivity (5000 ohms. cm) as shown in figure (6). This number of anode necessary to provide available current for protection during this soil, while in $(25 \mathrm{ohms.cm})$, three $\mathrm{Zn}$ anodes fair enough to satisfy purpose of protection.

However, figures $(7 \& 8)$ also shows that the number of anodes increased with increased of soil resistivity for $\mathrm{Al}$ and $\mathrm{Mg}$ anodes respectively. In contrast, weight of anodes decrement with increment of soil resistivity as shown in figures (9-11) for $\mathrm{Zn}, \mathrm{Al}$ and $\mathrm{Mg}$ anodes respectively. So that, four $\mathrm{Al}$ anodes have $581 \mathrm{~kg}$ available in the soil has $(25 \mathrm{ohms.cm})$ resistivity, while $842 \mathrm{Kg}$ for three $\mathrm{Al}$ anodes suitable in the soil of (5000 ohms.cm).

Weights of $\mathrm{Zn}, \mathrm{Al}$ and $\mathrm{Mg}$ anodes increased respectively for all different soil resistivity's. Decision of choose ether ones among these types of anodes depend mainly on the economic, availability, ease of production these anodes without oxidation and work area. 


\section{Conclusions:}

Soil resistivity has great effect on the design of sacrificial cathodic protection system of a pipeline steel of oil. The results obtained showed that the numbers, current output increased while weights decreased with increased of soil resistivity of all types of anodes have been used.

High soil resistivity (5000 ohms.cm) required low current output $(0.015$, 0.012 and 0.042 Amps) for $\mathrm{Zn}, \mathrm{Al}$ and $\mathrm{Mg}$ anodes respectively. Since low current obtained at this soil, so high number of anodes required to satisfy the purpose of protection. 


\section{List of symbols:}

A Total structure surface area in square feet

CE Coating efficiency

d Diameter of the backfill column in feet (specified by supplier)

$d_{s} \quad$ Diameter of steel pipe

E Anode's driving potentia

I Total protective current

$\mathrm{I}_{\mathrm{i}} \quad$ Required current density

L Length of the backfill column in feet (specified by supplier)

L Life time in years

$\mathrm{L}_{\mathrm{s}} \quad$ Length of steel pipe

$\mathrm{N} \quad$ Number of anodes

$\mathrm{R} \quad$ Coating resistance, in ohms per square feet

$\mathrm{R}_{\mathrm{a}} \quad$ Anode-to-electrolyte resistance in ohms

Rc Structure-to-electrolyte resistance

$\mathrm{R}_{\mathrm{T}} \quad$ The total resistance

$\mathrm{R}_{\mathrm{w}} \quad$ Anode lead wire resistance

W Weight of one anode in pounds

$\rho \quad$ Soil resistivity in ohms 


\section{References:}

1. J. Paul Guyer, P.E. and R.A, Introduction to Cathodic Protection, J. Paul Guyer, USA 2009.

2. A.H. El-Shazly, H.A. Al-Turaif, Improving the Corrosion Resistance of Buried Steel by Using Polyaniline Coating, Int. J. Electrochem. Sci., vol . 7, p p $211-2212012$.

3. Available at http://www.pdhengineer.com/pages/MA-4003.htm.

4. Perez N., Electrochemistry and corrosion science, Kluwer academic publisher, USA2004.

5. James B. Bushman and P.E., Impressed Current Cathodic Protection System design, Bushman \& Associates, Inc., USA.

6. L.L. Sheir, R. A. Jarman and G.T. Burstein, Corrosion volume 1 Metal /Environmental Reactions, A division of reed educational and professional publishing LTd, UK 2000 .

7. V. Ashworth, Principles of Cathodic Protection, B.V., Third edition, volume 2, pp 3-28 2010.

8. A. Ucsc, Education and Training for corrosion control, West Virginia University, Morgantown 2011.

9. U.F., 2005, Cathodic Protection, Iraq Virtual Science Library, USA.

10.Hafiz, M.H, Modeling of Pipeline Corrosion Control by Cathodic Protection, Ph.D, Thesis, Department of Production and Metallurgy Eng. University of Technology, Baghdad 2006. 


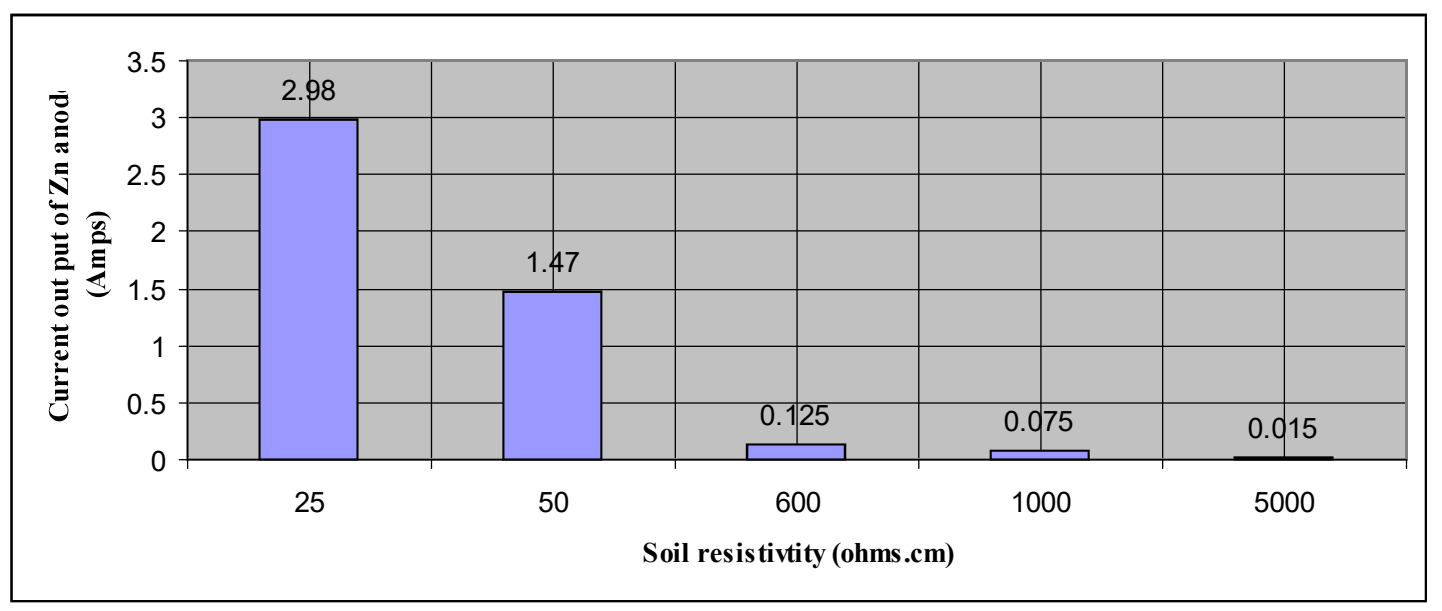

Fig. (3) Current output Vs soil resistivity of $\mathrm{Zn}$ anode

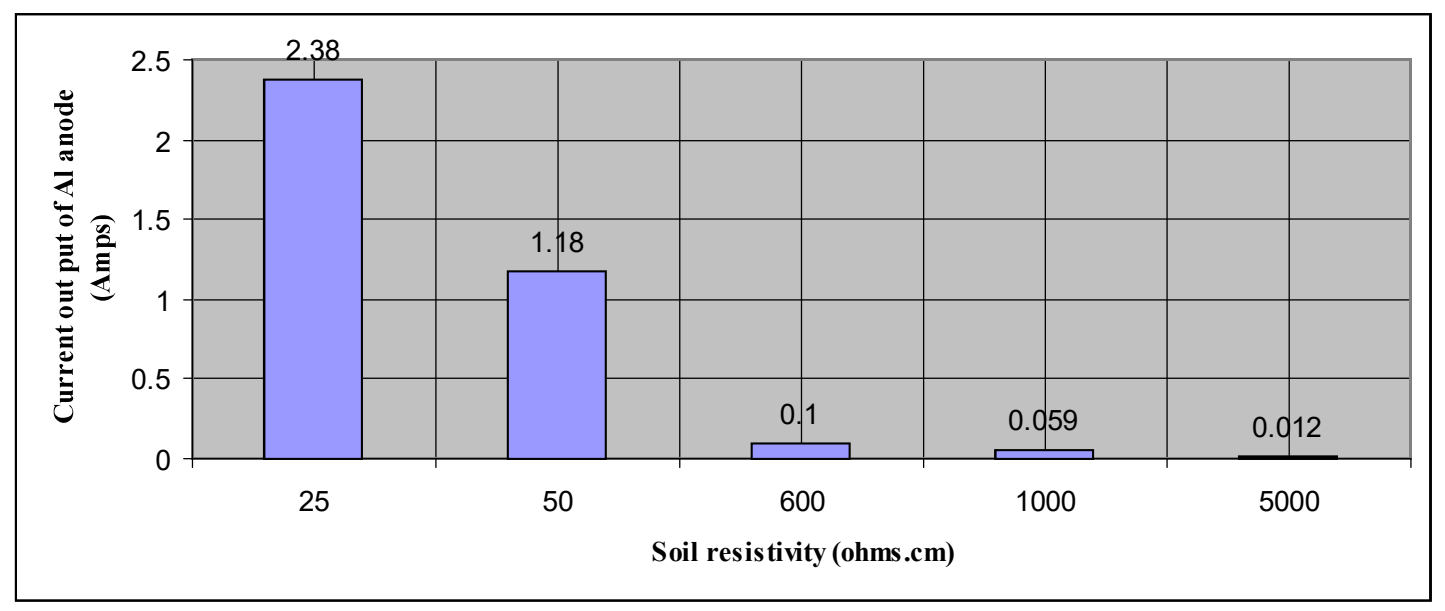

Fig.(4) Current output Vs soil resistivity of anode

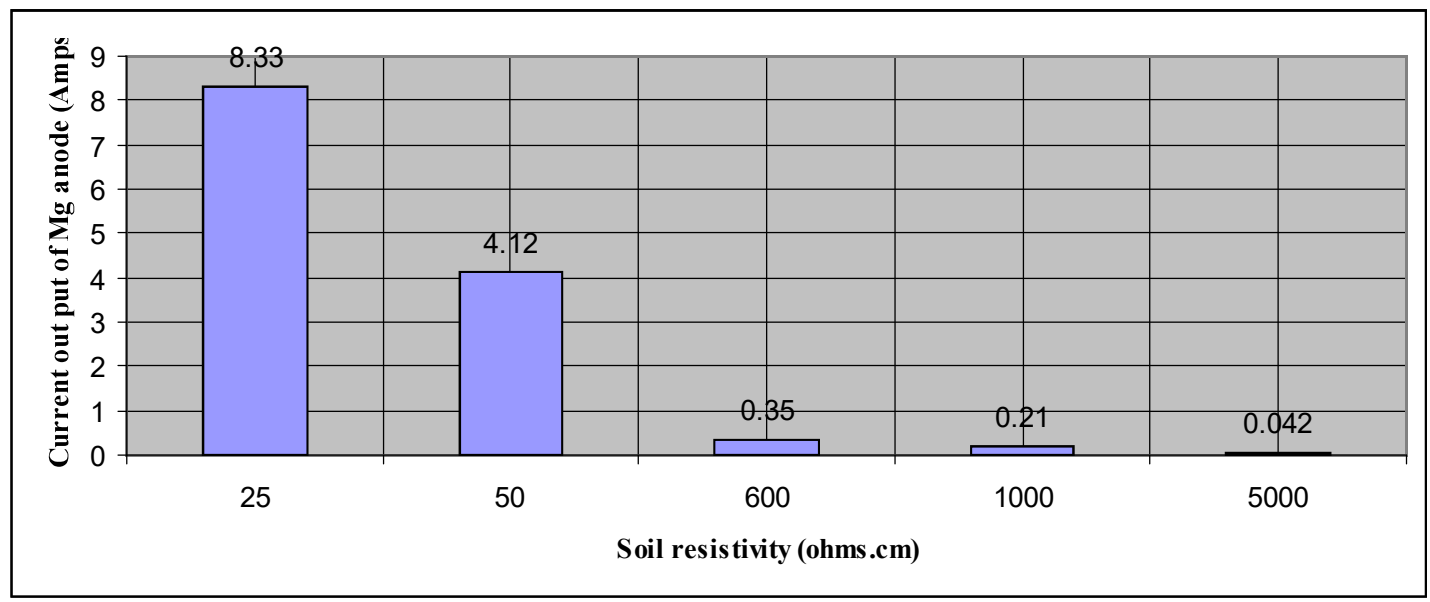

Fig.(5) Current output Vs soil resistivity of Mg anode 


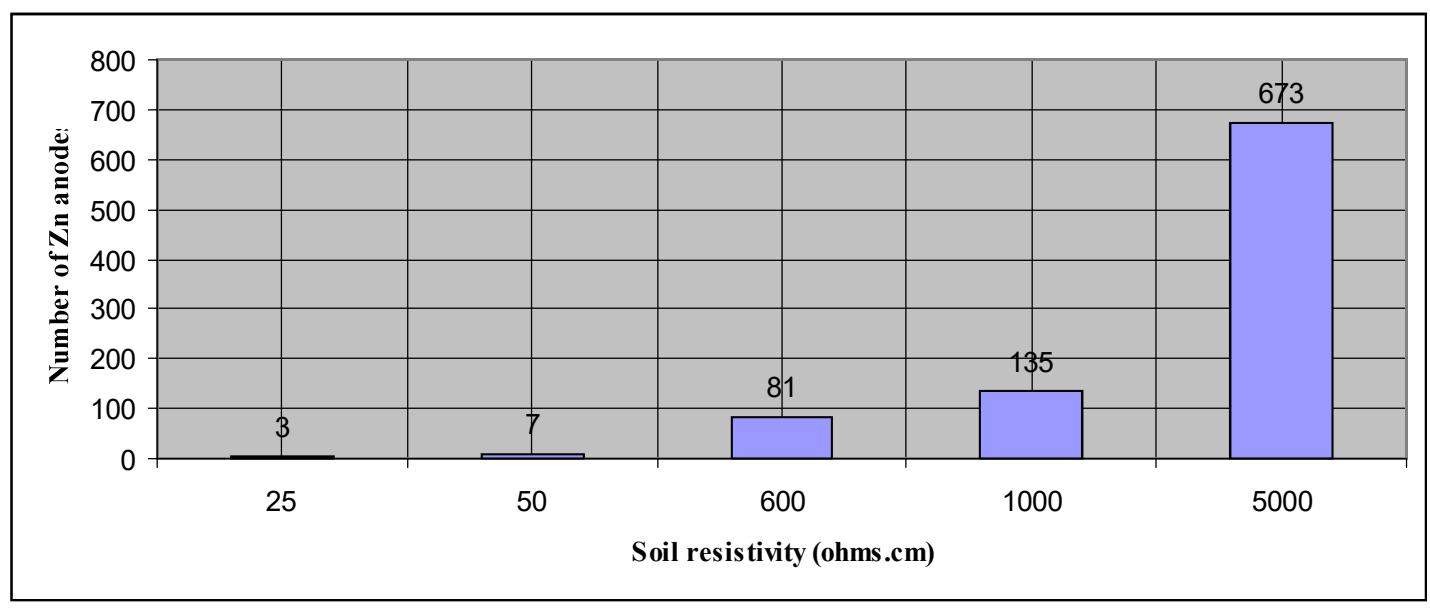

Fig. (6) Number of $\mathrm{Zn}$ anode Vs soil resistivity

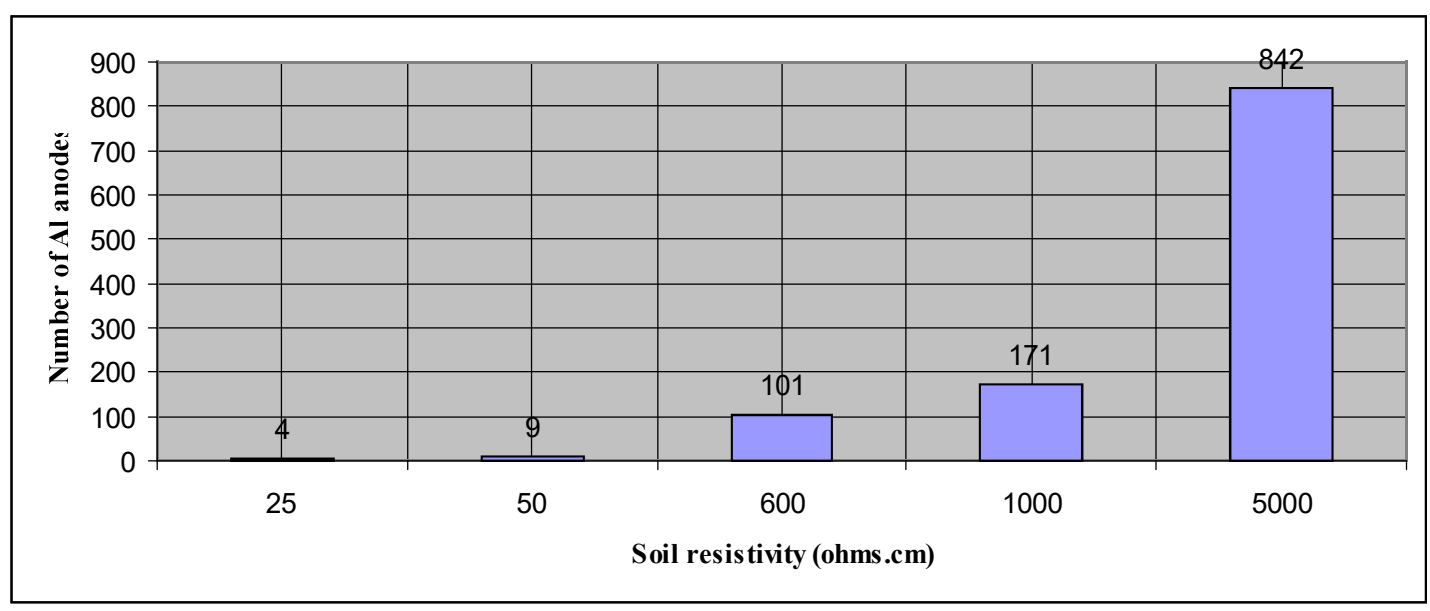

Fig. (7) Number of anode Vs soil resistivity

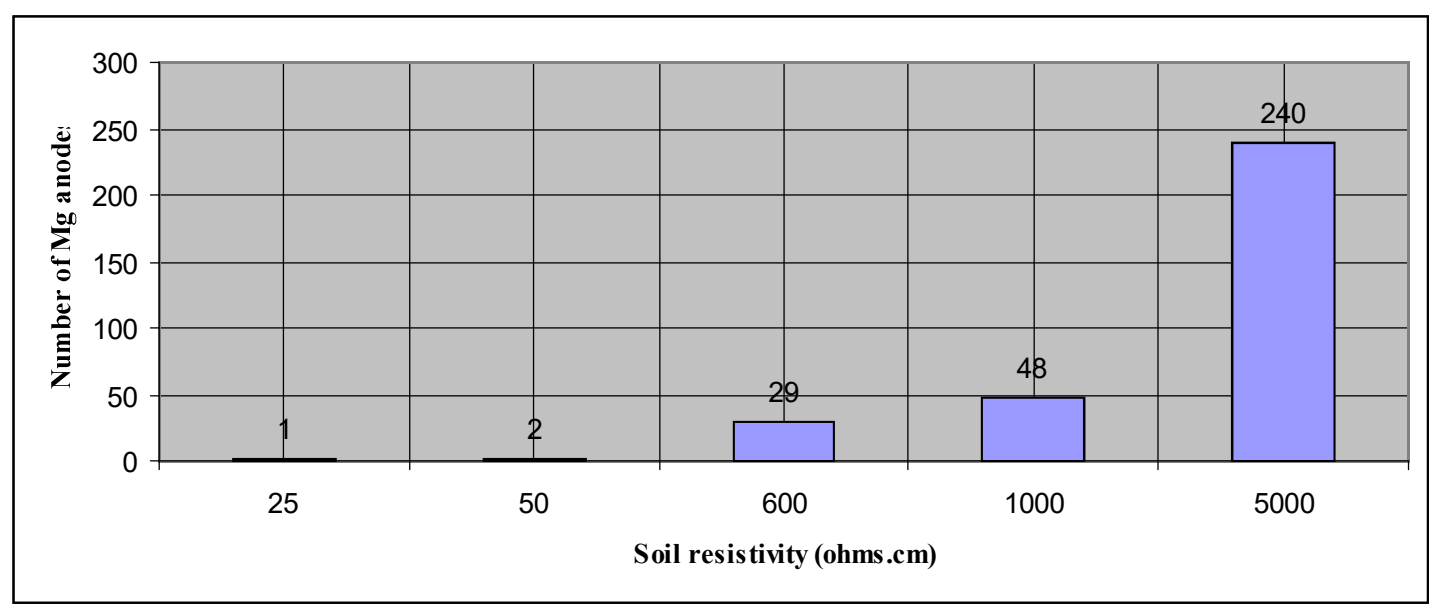

Fig. (8) Number of Mg anode Vs soil resistivity 


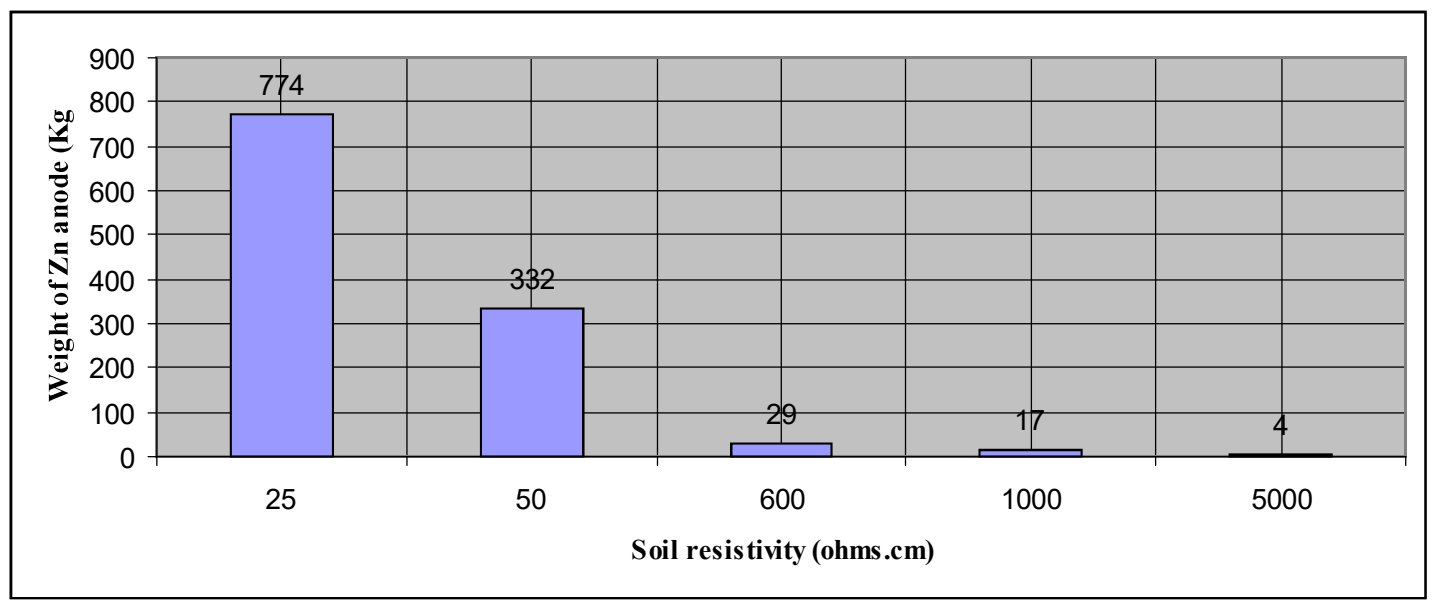

Fig. (9) Weight of $\mathrm{Zn}$ anode Vs soil resistivity

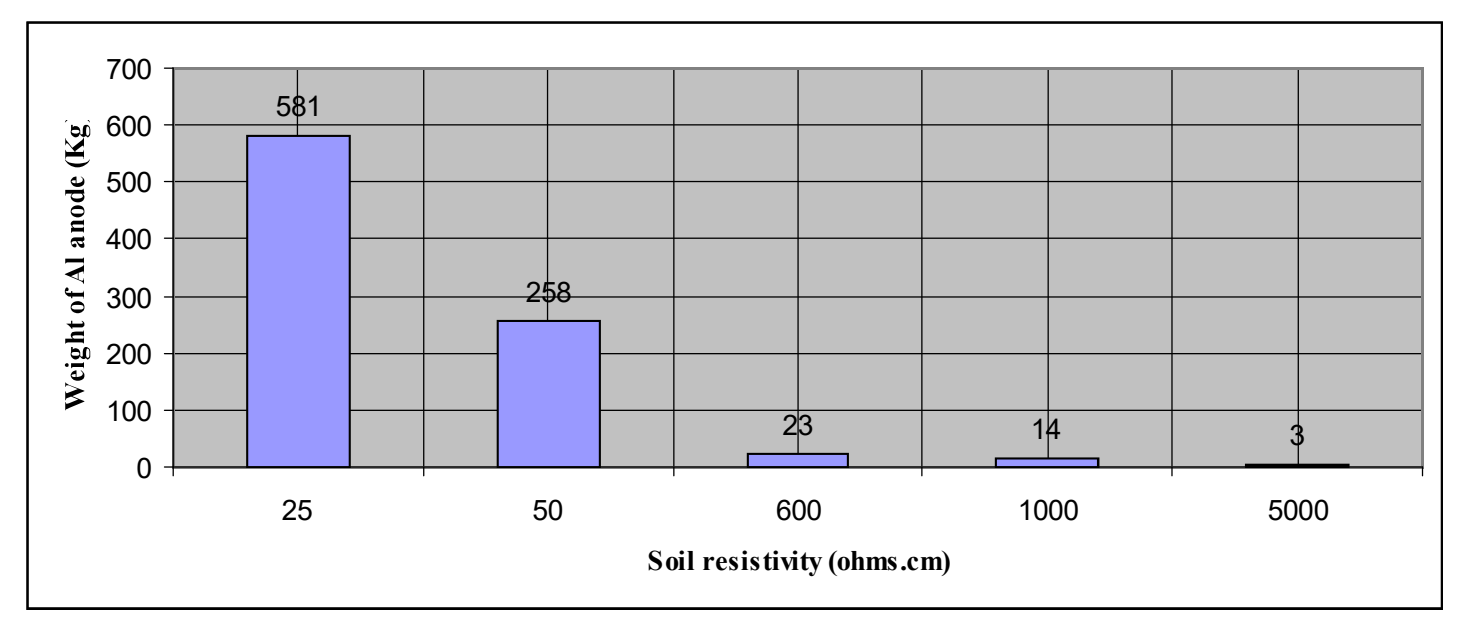

Fig. (10) Weight of Al anode Vs soil resistivity

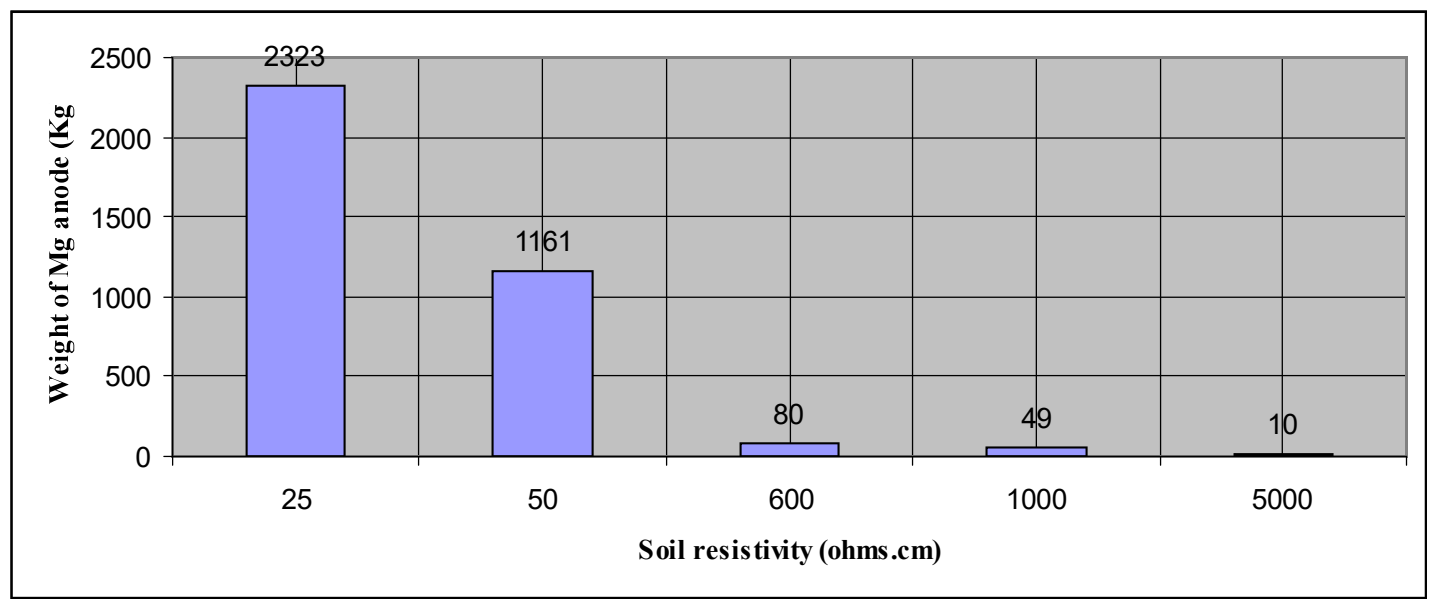

Fig.(11) Weight of Mg anode Vs soil resistivity 